\title{
A Educação a Distância no Brasil e a inserção da Universidade Federal do Ceará (UFC) nesse contexto
}

\section{Distance education in Brazil and the insertion of the Federal University of Ceará (UFC) in this context}

\section{La educación a distancia en Brasil y la inserción de la Universidad Federal de Ceará (UFC) en ese contexto}

Souza, Francisco Wagner de ${ }^{1}$ (Fortaleza, CE, Brasil)

ORCID ID: https://orcid.org/0000-0003-3011-2938 Alexandre, João Welliandre Carneiro² (Fortaleza, CE, Brasil) Orcid: https://orcid.org/0000-0000-0000-0000

Andriola, Wagner Bandeira ${ }^{3}$ (Fortaleza, CE, Brasil) Orcid: https://orcid.org/0000-0001-6459-0992 Cavalcante, Sueli Maria de Araújo 4 (Fortaleza, CE, Brasil) Orcid: https://orcid.org/ 0000-0002-0698-2485 Thomáz, Antônio Clécio Fontelles ${ }^{5}$ (Fortaleza, CE, Brasil) Orcid: https://orcid.org/0000-0003-4263-4194

\section{Resumo}

Desde os primeiros anos do século $X X$, a educação a distância $(E a D)$ vem sendo utilizada no Brasil como uma alternativa para a expansão e democratização do ensino em diferentes níveis, possibilitando a capacitação de profissionais formados, a obtenção de uma pós-graduação ou, em muitos casos, a primeira graduação, inclusive, para camadas da população com limitações financeiras, de tempo e geográficas, que, sem esse recurso, jamais poderiam alcançar essa meta. Nesse sentido, a Universidade Federal do Ceará (UFC) tem desenvolvido um papel muito importante para a educação do estado do Ceará, através de diversas experiências na modalidade, sobretudo, através de seus cursos de graduação a distância, ofertados pelo Instituto UFC Virtual. O objetivo deste artigo é descrever a evolução da educação a distância no Brasil e relatar as experiências desenvolvidas na UFC para se inserir na modalidade. Para tanto, fez-se uma pesquisa bibliográfica através de textos elaborados por estudiosos da área. Conclui-se que a EaD no Brasil tem cumprido um papel fundamental na educação nacional, favorecendo o aumento do número de matriculas no ensino superior e contribuindo para a expansão e democratização do ensino no país. Verifica-se ainda que a UFC, em 18 anos, desde a criação do Instituto UFC Virtual, tem contribuído fortemente para o aumento de números de matriculas na instituição e levado a oportunidade de formação para as diversas regiões do estado do Ceará.

Palavras-chave: Educação a distância. Universidade virtual. Universidade aberta.

\begin{abstract}
Since the early twentieth century, the distance education has been used in Brazil as an alternative for the expansion and democratization in different levels, making possible the training of many people, including, that of the popular layers with financial, time and geographic limitations, that, without this resource, they could never achieve that goal. In this sense, the Federal University of Ceará (UFC) has developed a very important role to the education of the state of Ceará, through diverse experiences in the modality, specially, through their distance graduate courses, offered by UFC Virtual Institute. The purpose of this paper is to describe the evolution of the distance education in Brazil and report the experiences developed in the UFC to insert itself into the modality. For this, a bibliographic search was carried out through texts prepared by scholars in the field. It is concluded that the distance education in

\footnotetext{
Professor de Língua Espanhola da Universidade Federal do Ceará e atua na Casa de Cultura Hispânica. prof.wagnersouza@ufc.br

2 Professor Titular da Universidade Federal do Ceará.jwca@ufc.br

${ }^{3}$ Professor Titular da Universidade Federal do Ceará (UFC) e Coordenador do Mestrado Profissional em Políticas Públicas e Gestão da Educação Superior (POLEDUC).w andriola@yahoo.com

${ }^{4}$ Professora associada da Universidade Federal do Ceará (UFC). suelicavalcante@ufc.br

5 1995. Atualmente é Prof. Titular Aposentado da Universidade Federal do Ceará e Prof. adjunto da Universidade Estadual do Ceará.clecio@larces.uece.br
} 
Brazil has played a key role in the national education, favoring the increase of the number of enrollments in higher education and contributing to the expansion and democratization of education in the country. It is also noted that UFC, in 18 years, since creation of the UFC Virtual Institute, has contributed strongly to the increase of number of enrollments in the institution and taken the training opportunity to the several regions of the state of Ceará.

Keywords: Distance education. Virtual university. Open university.

\section{Resumen}

Desde los primeros años del siglo XX, la educación a distancia $(\mathrm{EaD})$ ha sido utilizada en Brasil como una alternativa para la expansión y democratización de la enseñanza en diferentes niveles, posibilitando la capacitación y formación de muchas personas, incluso, de sectores de la población con limitaciones financieras, de tiempo y geográficas, que, sin ese recurso, jamás podrían hacerlo. En ese sentido, la Universidad Federal de Ceará (UFC) ha desarrollado un papel muy importante para la educación del estado, a través de diversas experiencias en la modalidad, sobre todo, a través de sus cursos de pregrado a distancia, ofrecidos por el Instituto UFC Virtual. El objetivo de este artículo es describir la evolución de la EaD en Brasil y relatar las experiencias desarrolladas en la UFC para inserirse en la modalidad. Para ello, se hizo una investigación bibliográfica a través de textos elaborados por estudiosos del área. Se concluye que la EaD en Brasil ha cumplido un papel fundamental en la educación nacional, favoreciendo el aumento del número de matrículas en la enseñanza superior y contribuyendo para la expansión y democratización de la enseñanza en el país. Se verifica aún que la UFC, en 18 años, desde la creación del Instituto UFC Virtual, ha contribuido fuertemente para el aumento del número de matrículas en la institución y llevado la oportunidad de formación para las diversas regiones del estado de Ceará.

Palabras Clave: Educación a distancia. Universidad virtual. Universidad abierta.

\section{Introdução}

O Brasil teve suas primeiras manifestações de educação a distância (EaD) tardiamente em relação a outros países. Enquanto os primeiros registros da EaD no âmbito mundial datam de 1700, apenas nos anos 1900 o Brasil registrou suas primeiras experiências voltadas à modalidade (ANDRIOLA, 2019).

No Brasil, a EaD se manifesta desde o final do século XIX, através de cursos técnicos, cursos de idiomas e cursos supletivos, mas apenas a partir da década de 1990, com o surgimento de uma legislação específica, ela passou a vigorar também no ensino superior. A Lei de Diretrizes e Bases da Educação Nacional (LDB), Lei nº. 9.394, de dezembro de 1996, e os Decretos n. 2494, de 10 de fevereiro de 1998; Decreto n. 2561, de 27 de abril de 1998 e a Portaria Ministerial n. 301, de 7 de abril de 1998, oficializam e regulamentam a educação a distância no país como modalidade válida e equivalente para todos os níveis de ensino (MARCUZZO, 2013; ANDRIOLA; LOUREIRO, 2005).

O crescimento vertiginoso da EaD no Brasil se deu, principalmente, pela contribuição do Programa de Apoio a Planos de Reestruturação e Expansão das Universidades Federais Brasileiras (Reuni), instituído em 2007 pelo decreto n. 6.096, de 24 de abril, que possibilitou uma grande expansão e democratização do ensino 
superior. O programa tinha como objetivo ampliar o acesso e a permanência na educação superior e para tanto o governo intensificou essa política nas universidades, fazendo com que, além da ampliação do número de vagas, fossem criados novos cursos, novas Instituições Federais de Educação Superior (IFES), polos de educação a distância em várias cidades, além de possibilitar um grande aumento na contratação de professores e técnico-administrativos (LAVOR; ANDRIOLA; LIMA, 2015).

A Universidade Federal do Ceará (UFC) iniciou suas atividades em EaD ainda em 1997, através do Grupo de Pesquisa em Educação a Distância, coordenado pelo professor Dr. Mauro Cavalcante Pequeno, que visava aplicar as TIC para auxiliar os problemas de aprendizagem dos alunos de regiões marginais urbanas do ensino básico. $O$ conhecimento acumulado pelo grupo contribuiu para a institucionalização da EaD na UFC, em 2003, quando surgiu o Instituto UFC Virtual. Fato que tornou a UFC como uma instituição com reconhecido histórico ligado a educação a distância, não só no cenário cearense como também no cenário nacional (LIMA; ANDRIOLA, 2013).

A partir do exposto, justifica-se o presente trabalho, cujo objetivo é descrever a evolução histórica da educação a distância e como a Universidade Federal do Ceará se posicionou nesse cenário.

\section{As Gerações da Educação a Distância no Brasil}

Para descrever a história da EaD no Brasil, este trabalho apoiar-se-á nos estudos de Maia e Mattar (2007), que classificam a evolução da educação a distância em três gerações: a primeira sendo a dos cursos por correspondências; a segunda, a das novas mídias (televisão, o rádio, as fitas de áudio e vídeo e o telefone) e das universidades abertas; e a terceira, a da EaD on-line, conforme se ilustra na Figura 1. 
Figura 1- As três gerações da educação a distância

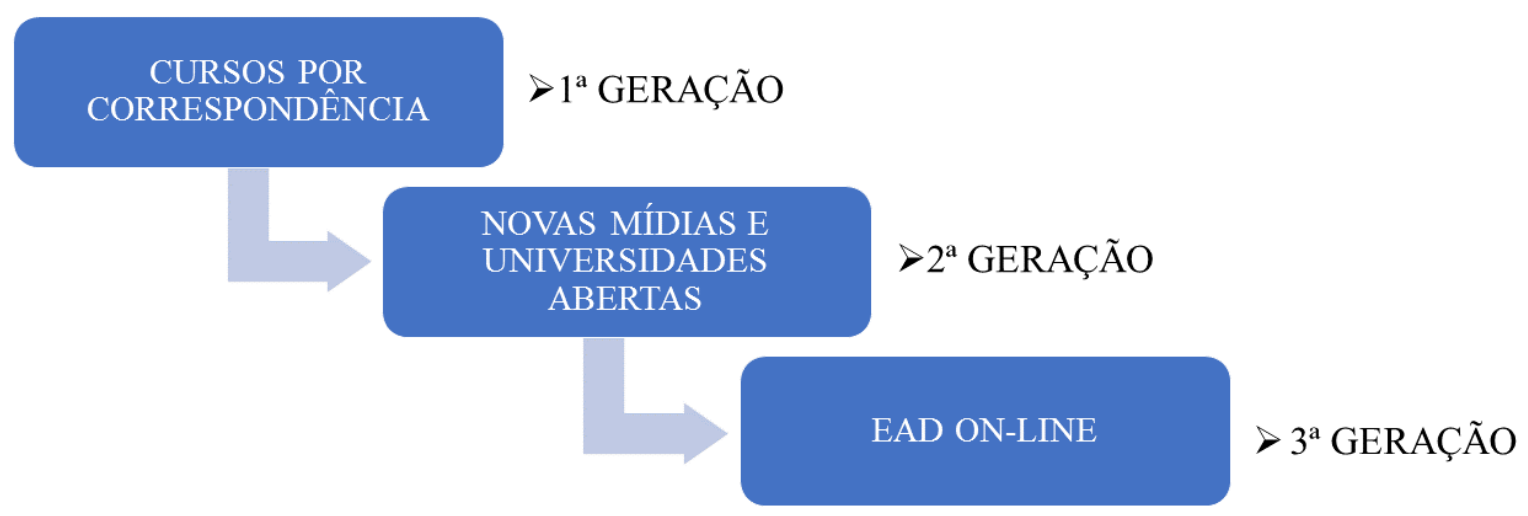

Fonte: Elaborado pelos autores, com base em Maia e Mattar (2007)

A Figura 1 representa a evolução histórica da EaD no Brasil em um período de mais ou menos 100 anos. Desde sua primeira geração, a dos cursos por correspondência, no início do século XX; passando pela segunda geração, 20 anos depois, quando surgiram as novas mídias como rádio e televisão e a criação das universidades abertas; até a chegada da Internet, no final do século, quando se iniciou a terceira geração, a EaD on-line.

\section{A primeira geração da educação a distância: cursos por correspondência}

Ainda que anúncios em jornais de circulação no Rio de Janeiro já oferecessem cursos profissionalizantes por correspondência em 1900, é apenas em 1904 que há o primeiro registro oficial da EaD no Brasil (ALVES, 2009).

Esses primeiros registros se referem às Escolas Internacionais, que eram filiais de uma organização norte-americana, as quais existem até hoje e está presente em diversos países. Tratava-se de instituições privadas que ofereciam cursos voltados para as pessoas que estavam em busca de empregos, sobre tudo nos setores de comércio e serviços. Nesse período, o ensino era praticado por correspondência e os materiais didáticos eram enviados pelos correios, que usavam os trens como principal meio de transporte (ALVES, 2009; MAIA; MATTAR, 2007).

Segundo Maia e Mattar (2007), nesse momento o país vivia uma crise na educação nacional e, portanto, não foi dada devida importância à educação a distância. Além disso, a modalidade sofria com as dificuldades enfrentadas com o uso 
dos correios. Todos esses percalços fizeram com que as autoridades educacionais e órgãos governamentais dessem pouco incentivo para o desenvolvimento do sistema.

A primeira geração da EaD no Brasil durou quase 20 anos (1904-1923). Durante todo esse tempo manteve como base o material impresso, mas, em 1923, agora com várias iniciativas bem sucedidas e com o complemento do rádio, da televisão e do computador, a EaD ganha um novo impulso. E é nesse cenário que surge a segunda geração da EaD no Brasil.

\section{A segunda geração da educação a distância: novas mídias e universidades abertas}

Uma das primeiras manifestações da segunda geração da EaD no Brasil se deu em 1923, quando um grupo liderado por Henrique Charles Morize ${ }^{6}$ e Edgard Roquette-Pinto ${ }^{7}$ criou a Rádio Sociedade do Rio de Janeiro. Essa nova modalidade oferecia cursos de português, francês, silvicultura, literatura francesa, esperanto, radiotelegrafia e telefonia (MAIA; MATTAR, 2007).

Segundo afirma Alves (2009, p.9), "a principal função da emissora era possibilitar a educação popular, por meio de um então moderno sistema de difusão em curso no Brasil e no mundo". Essa iniciativa, porém, trouxe preocupação aos governantes, que temiam a transmissão de programas considerados subversivos, especialmente pelos revolucionários da década de 1930.

Em 1934, seguindo a mesma linha da Radio Sociedade, Roquette-Pinto instalou, no Rio de Janeiro, a Rádio-Escola Municipal, um projeto para a então Secretaria Municipal de Educação do Distrito Federal. Nessa iniciativa os estudantes tinham acesso prévio a folhetos e esquemas de aulas, e recebiam contato da emissora através de correspondências (ALVES, 2011).

Em 1936, consoante Alves (2009), a Rádio Sociedade foi doada ao Ministério da Educação e Saúde. No ano seguinte o órgão criou o Serviço de Radiodifusão Educativa do Ministério da Educação. Esse fato impulsionou a implementação de inúmeros programas nos anos seguintes.

${ }^{6}$ Engenheiro industrial francês, naturalizado brasileiro. Atuou também como astrônomo e teve papel de destaque na pesquisa em várias áreas vizinhas à física e à astronomia. Participou ativamente da criação da Rádio Sociedade do Rio de Janeiro, onde também foi presidente. Para mais informações:http://www.fiocruz.br/brasiliana/cgi/cgilua.exe/sys/start.htm?infoid=153\&sid=30.

${ }^{7}$ Médico, professor e antropólogo brasileiro. Membro da Academia Brasileira de Letras. É considerado o pai da radiodifusão no Brasil. Para mais informações: https://wp.ufpel.edu.br/roquettepinto/files/2017/03/Quem-Foi-Edgar-Roquette-Pinto.pdf. 
Em 1941, surgiu a primeira Universidade do $\operatorname{Ar}$ (Unar). Dois anos depois, em 1943, teve início a Escola Rádio-Postal e nesse mesmo ano, a igreja Adventista criou a Voz da Profecia. Esta tinha o objetivo de oferecer cursos bíblicos aos seus ouvintes (ALVES, 2009; ALVES, 2011). Segundo Maia e Mattar (2007), a experiência foi tão bem sucedida que se transformou mais tarde no Sistema Adventista de Comunicação, que inclui, além de A Voz da Profecia, a Rede Novo Tempo de Rádio, a Rede Novo Tempo de TV e o programa Está Escrito.

Segundo Alves (2009), em 1946, o Serviço Nacional de Aprendizagem Comercial (SENAC) iniciou suas atividades e já no ano seguinte, 1947, junto ao Serviço Social do Comércio (SESC) e as emissoras de rádio associadas recriaram a nova Universidade do $\operatorname{Ar}$ (a primeira tinha durado até 1944). A nova Universidade do Ar oferecia cursos radiofônicos comerciais, nos quais os alunos estudavam por meio de materiais impressos e as tarefas eram corrigidas por monitores. Essa experiência durou até 1961 (MAIA; MATTAR, 2007; ALVES, 2011).

A Igreja Católica, por meio da diocese de Natal, no Rio Grande do Norte, criou, em 1959, algumas escolas radiofônicas, o que deu origem ao Movimento de Educação de Base (MEB), marco na educação a distância não formal no Brasil. O MEB, envolvendo a Conferência Nacional dos Bispos do Brasil e o Governo Federal, utilizou-se de um sistema rádio-educativo para a democratização do acesso à educação, promovendo o letramento de jovens e adultos (ALVES, 2009; ALVES, 2011; MAIA; MATTAR, 2007).

Projetos como o Movimento Brasileiro de Alfabetização (Mobral), criado em 1967 com o objetivo de alfabetizar a população urbana entre 15 e 35 anos, e o Minerva, criado em 1970 com o propósito de solucionar os problemas educacionais existentes com a implantação de uma cadeia de rádio e televisão, tiveram grande importância para a educação a distância via rádio no país, porém, como destaca Rubio (2011). Com a deflagração da ditadura militar, alguns projetos que usavam o rádio como meio de transmissão foram censurados, fato que comprometeu seriamente a rádio educativa brasileira. Segundo a autora, enquanto outros países utilizavam e aperfeiçoavam os modelos radiofônicos, a EaD via rádio no Brasil sofria um desmonte, o que levou o país a sofrer uma queda significativa no ranking internacional (RUBIO, 2011). 
Após quatro décadas de $\mathrm{EaD}$ usando como ferramenta de transmissão o rádio, surge a TV como uma alternativa para a modalidade. Em 1967, foi publicado o Código Brasileiro de Telecomunicações, que determinava que as emissoras de rádio e as televisões educativas deveriam incluir programas educativos em suas grades de atividades. Com isso, alguns grupos de poder tiveram o privilégio de receber concessões de televisões com fins específicos de educação. Um exemplo são as universidades e fundações, as quais receberam diversos incentivos para a instalação de canais de difusão educacional (ALVES, 2009).

Ainda em 1967, uma iniciativa que teve grande destaque, segundo Maia e Mattar (2007), foi o projeto Satélite Avançado de Comunicações Interdisciplinares (Projeto Saci). Tratava-se de um projeto concebido pelo Instituto Nacional de Pesquisas Espaciais (Inpe), que tinha como objetivo criar um sistema nacional de telecomunicações com o uso de satélite. O projeto foi considerado inovador e pioneiro, no entanto, foi encerrado em 1976.

Ainda segundo Alves (2009), em 1969, foi criado o Sistema Avançado de Tecnologias Educacionais. Esse sistema previa a utilização de ferramentas como o rádio, a televisão e outros meios aplicáveis. Em seguida, o Ministério das Comunicações baixou uma portaria que definia o tempo obrigatório e gratuito que as emissoras comerciais deveriam ceder à transmissão de programas educativos (SILVA; LIMA; ANDRIOLA, 2016).

Em 1972, foi criado o Programa Nacional de Teleducação (Prontel), que não durou muito tempo, devido ao surgimento, logo em seguida, do Centro Brasileiro de TV Educativa (Funtevê) como órgão integrante do Departamento de Aplicações Tecnológicas do Ministério da Educação e Cultura. Outras iniciativas de destaque nesse período foram as TVs universitárias, o Canal Futura, a TV Cultura, dentre outras (ALVES, 2009; LIMA, 2014).

Na década de 1970, a Fundação Roberto Marinho lançou um programa que mais tarde ficou conhecido como Telecurso 2000. Era um programa de educação supletiva a distância, voltadas para o $1^{\circ}$ e e $2^{\circ}$ graus. O Telecurso, além de disponibilizar salas pelo país para que os alunos assistam às transmissões e aos vídeos, utiliza livros, vídeos e transmissão por TV. Calcula-se que mais de 4 milhões de pessoas tenham sido beneficiadas pelo programa (MAIA; MATTAR, 2007). 
No início da década de 1990, teve início o programa Jornal da Educação, concebido e produzido pela Fundação Roquette-Pinto. Em 1995, esse programa passou a se chamar Salto para o Futuro e foi incorporado ao canal educativo da Secretaria de Educação a Distância do Ministério da Educação, a TV Escola. Mais um importante um marco na $\mathrm{EaD}$ nacional. Trata-se de um programa para formação continuada que utiliza diversas mídias como material impresso, TV, fax, telefone e Internet, além de encontros presenciais nas telessalas, que contavam com a mediação de um orientador de aprendizagem (MAIA; MATTAR, 2007).

É importante destacar que no início da década de 1990, as emissoras ficaram desobrigadas de ceder horários diários para transmissão dos programas educacionais, o que resultou em um grande retrocesso para a EaD baseada na TV. As iniciativas apresentadas até aqui estavam ligadas basicamente à capacitação de professores e aos ensinos fundamental e médio. $O$ ensino superior só começou a ser virtualizado a partir da década de 1979, através da iniciativa da Universidade de Brasília, que foi a primeira instituição a usar a EaD no ensino superior. Neste ano, criou o Programa de Ensino a Distância (PED), que ofereceu um curso de extensão universitária, além de oferecer cursos traduzidos da Open University.

De acordo com Alves (2011), a partir dos anos de 1990, a criação das Universidades Abertas, que já era um fenômeno exitoso na Europa, foi um acontecimento muito importante para a educação a distância no país. A primeira instituição nesses moldes foi a Universidade Aberta de Brasília, criada em 1992. Ainda segundo a autora, em 1996, foi criada, pelo Ministério da Educação, a Secretaria de Educação a Distância, dentro de uma política que privilegia a democratização e a qualidade da educação brasileira.

É nesse contexto que a educação a distância é oficializada no Brasil através da Lei de Diretrizes e Bases da Educação Nacional (Lei n. 9.394, de 20 de dezembro de 1996) em um capítulo que trazia quatro artigos relacionados ao credenciamento de instituições, à regulamentação, pela União, dos requisitos para registro de diplomas, à produção, controle e avaliação de programas de $\mathrm{EaD}$ e às condições operacionais para facilitar sua implementação (KIPNIS, 2009; ANDRIOLA; OLIVEIRA, 2015). 
É importante ressaltar, no entanto, que, segundo Alves (2011) e Kipnis (2009), mesmo com a criação da LDB, em 1996, a EaD só foi de fato regulamentada quase 10 anos depois, em 2005, pelo Decreto $n^{\circ}$ 5.622. Mesmo ano em que foi criada a Universidade Aberta do Brasil, uma parceria entre o MEC, estados e municípios que buscava integrar cursos, pesquisas e programas de educação superior a distância.

Desde então, as universidades abertas têm atuado com sucesso no âmbito da educação continuada de adultos. Sua flexibilidade de horário, de lugar e o método de ensino aplicado têm atraído cada vez mais interessados (ARAÚJO; ANDRIOLA; COELHO, 2018). Somando-se a isso, o uso do computador e, em especial, o uso da web como meios de transmissão de conhecimento favoreceram ainda mais a expansão da modalidade por todo o país. É então que surge a terceira geração da EaD, a EaD on-line.

\section{A terceira geração da educação a distância: EaD on-line}

O final dos anos de 1990 ficou marcado pela chegada da Internet, fato que revolucionou todos os setores do país e não poderia ser diferente com a modalidade de educação a distância, que foi muito beneficiada com tal advento, pois a incorporação das TIC ao sistema, resolveria, até certo ponto, um dos problemas da modalidade até então, a interação entre os indivíduos envolvidos.

Valente (2003) destaca que a Internet possibilitou uma interação professoraprendiz mais intensa e permitiu que o professor possa, mesmo que virtualmente, "estar junto" do seu aprendiz, podendo assim auxiliá-lo na elucidação de dúvidas e na resolução de problemas.

Nesse mesmo sentido, Kipnis (2009) ressalta que a década de 1990 caracterizou-se pela difusão da revolução nas TIC, o que, segundo ele, marcou o início efetivo da EaD nas instituições de educação superior. Nessa mesma década, surgiram os primeiros ambientes virtuais de aprendizagem, dentre eles o Eproinfo, o Teleduc e o Moodle (LIMA, 2014).

A partir dos anos 2000, muitas iniciativas baseadas no uso das TIC foram desenvolvidas no campo da EaD. Um exemplo foi a criação de uma rede regional de $\mathrm{EaD}$, o Consórcio Centro de Educação a Distância do Estado do Rio de Janeiro (Cederj), que apoia universidades estaduais e federais na oferta de cursos de 
licenciatura em pedagogia, ciências biológicas e pedagogia, todos credenciados pelo MEC (MAIA; MATTAR, 2007).

Ainda no ano 2000, segundo Kipnis (2009), a Secretaria de Educação de Minas Gerais, em parceria com 18 universidades; centros universitários e outras IES, criou o Projeto Veredas. Esse projeto tinha como o objetivo oferecer cursos para professores dos quatro anos iniciais do ensino fundamental das redes estadual e municipal, que ainda não tinham formação em nível superior. As vagas foram distribuídas em 21 polos regionais e 29 subpolos.

Outra iniciativa importante para essa geração da $\mathrm{EaD}$ foi a criação, ainda em 2000, do Instituto Universidade Virtual Brasileira, uma Rede Brasileira de Educação a Distância concebida e liderada pela Universidade Anhembi Morumbi, que foi credenciado pelo MEC para ofertar cursos de graduação. Em 2003, o instituto recebeu autorização para ofertar quatro cursos de bacharelado por Internet. (KIPNIS, 2009; MAIA; MATTAR, 2007; ANDRIOLA; GOMES, 2017).

Em 2005 a EaD deu um grande salto na sua evolução no país com a regulamentação do já mencionado Sistema Universidade Aberta do Brasil. A UAB foi criada em 2005 e oficializada pelo Decreto n. 5.800 (de 8 de junho de 2006) como um consórcio de Instituições Públicas de Ensino Superior, Estados e Municípios, sob a coordenação da Secretaria de Educação a Distância do Ministério da Educação (MAIA; MATTAR, 2007).

\begin{abstract}
O principal objetivo do Programa UAB foi a criação de um sistema composto por instituições públicas de ensino superior como Universidades Federais e centros federais de educação tecnológica com a adesão de municípios e estados, que teve como finalidade a democratização, expansão e interiorização da oferta de cursos e programas de educação superior público e gratuito no Brasil (PELLI; VIEIRA, 2018).
\end{abstract}

A partir de então, diversas IES, tanto do setor público como privado, passaram a oferecer variados cursos a distância apoiados, sobre tudo, na Internet para praticamente todas as regiões do país, alcançando especialmente aqueles que tenham dificuldades financeiras, geográficas ou de tempo e que, portanto, não poderiam se inserir no sistema presencial. 


\section{A educação a distância na Universidade Federal do Ceará: o Instituto UFC Virtual}

A primeira experiência da UFC com a educação a distância se deu em 1997, através das atividades do Projeto EDUCADI, um projeto-piloto de educação a distância em Ciência e Tecnologia, implementado pelo Ministério da Ciência e Tecnologia, por meio do Conselho Nacional de Desenvolvimento Científico e Tecnológico (CNPq). Esse projeto tinha como objetivo "aplicar tecnologias da informação e da comunicação em educação a distância para auxiliar na construção de projetos dentro das escolas, com o intuito de minimizar os problemas de aprendizagem dos alunos de regiões marginais urbanas do ensino básico" (UNIVERSIDADE FEDERAL DO CEARÁ, [201-], documento em linha).

O EDUCADI foi aplicado em quatro estados da federação: Ceará, Brasília, Rio Grande do Sul e São Paulo. Cada um desses estados atendeu 10 escolas públicas da rede estadual. No caso do Ceará, as escolas que fizeram parte do projeto foram: o Centro de Referência Prof ${ }^{a}$. Maria José Santos Ferreira Gomes; o Centro Educacional Moema Távora; a Escola de $1^{\circ}$ e $2^{\circ}$ Grau Maria da Conceição Porfírio Teles; a Escola de $1^{\circ}$ Grau Marechal Juarez Távora; a Escola de $1^{\circ}$ Grau Paulo Ayrton; a Escola de $2^{\circ}$ Grau Adauto Bezerra; a Escola Johnson; a Escola Noel Hugnen, o Instituto de Educação do Ceará e o Centro de Informática Educativa (REIS, 2005; SANTIAGO, 2017).

No Ceará, o projeto foi coordenado pelo Prof. Dr. Mauro Cavalcante Pequeno, professor titular da UFC, e teve como coordenador pedagógico o Prof. Ms. Robson Carlos Loureiro. O projeto estava ligado à Secretaria de Ciência e Tecnologia do estado e ao Departamento de Computação da UFC.

Em 1998, de acordo com a Universidade Federal do Ceará ([201-]), o grupo de pesquisa do Prof. Dr. Mauro Pequeno, que participava do EDUCADI, organizou o IX Simpósio Brasileiro de Informática na Educação, considerado como um dos maiores eventos do gênero em toda a América do Sul.

Em 2001, segundo consta no histórico, o grupo ingressou na UNIREDE Universidade Virtual Pública do Brasil, que reunia mais 61 instituições públicas envolvendo cursos de graduação, pós-graduação, extensão e educação continuada.

Em 2003, na gestão do Magnífico Reitor Prof. Roberto Cláudio Frota Bezerra (1995 - 2003), a UFC criou o Instituto UFC Virtual. Esse Instituto, que ainda 
está ativo até hoje, 2020, tem como objetivo "potencializar o acesso ao ensino de qualidade, sendo uma via aberta para a democratização do conhecimento" e a missão de "conceber e implantar ações que utilizem metodologias, tecnologias, linguagens e práticas educativas inovadoras, na perspectiva de uma educação em rede" (UNIVERSIDADE FEDERAL DO CEARÁ, [201-], documento em linha).

No momento de sua criação, o Instituto teve como diretor geral, o Prof. Dr. Miguel Araújo; como diretor técnico, o Prof. Dr. Mauro Cavalcante Pequeno e, pouco tempo depois, ainda em 2003, o Prof. Dr. José Aires de Castro Filho como Diretor Pedagógico. Em 2005, a direção geral do Instituto Virtual foi assumida pelo Prof. Dr. Mauro Pequeno e neste mesmo ano o Instituto participou do SBTVD - Sistema Brasileiro de Televisão Digital -, um projeto de definição do padrão de TV Digital Brasileiro.

Consoante Carneiro (2010), os primeiros passos do Instituto se deram de fato em 2006, através de um projeto-piloto em parceria com o Banco do Brasil (BB) instituição financiadora do projeto - que consistia em um curso de Bacharelado em Administração para os funcionários do próprio BB. Para este curso, segundo consta no Anuário Estatístico da UFC (2009), foram ofertadas 250 vagas, distribuídas entre 7 polos, localizados em Aracati, Aracoiaba, Beberibe, Fortaleza, Juazeiro do Norte, São Gonçalo do Amarante e Sobral. Esse projeto serviu como modelo para a parceria da UFC, através do Instituto Virtual e a Universidade Aberta do Brasil.

De acordo com dados obtidos através do Anuário Estatístico da UFC (2009), no ano seguinte, em 2007, após a experiência com o projeto-piloto e agora sendo a UFC participante da UAB, surgiram novos polos e as primeiras turmas de Licenciatura. Foram 880 vagas distribuídas entre os polos de Aracati, Aracoiaba, Barbalha, Caucaia (2 polos), Meruoca, Quixadá, Quixeramobim (2 polos), Russas, São Gonçalo do Amarante e Ubajara. Neste primeiro momento, foram ofertados os cursos de Licenciatura em Física, Letras/Inglês, Letras/português, Matemática e Química. Além disso, foram ofertadas mais 100 vagas de Bacharelado em Administração, divididas entre 2 polos de Caucaia e o polo de Quixadá.

Em 2008, foram criados os polos de Brejo Santo, Camocim, Campos Sales, Ipueiras, Itapipoca, Jaguaribe, Maranguape, Missão Velha, Orós, Piquet Carneiro, Quiterianópolis e Tauá. Nesse ano, além dos cursos já conhecidos, foi 
ofertado também o curso de Licenciatura em Letras/Espanhol. No total, foram 2.100 vagas ofertadas nesse ano (UNIVERSIDADE FEDERAL DO CEARÁ, 2009).

$O$ modelo de EaD aplicado na UFC é o semipresencial, que consiste em uma mescla de aulas a distância e aulas presenciais. Estas últimas realizadas nos polos de apoio presencial localizados na cidade sede do curso. Sendo $80 \%$ dos cursos realizados a distância e $20 \%$ de forma presencial.

Os polos de apoio presencial devem oferecer uma estrutura física para os alunos capaz de contribuir para o estabelecimento e manutenção de vínculo entre aluno e universidade. Esses polos devem contar com as seguintes facilidades: salas de estudo; microcomputadores conectados à Internet com multimeios, videoconferências e acesso banda larga; supervisão acadêmica de especialistas na área; biblioteca e recursos audiovisuais (QUIRINO, 2017).

São nos polos presenciais que ocorrem exames de cada disciplina; as apresentações de seminários; a tutoria presencial semanal ou diária, para esclarecimento de dúvidas e tutoria à distância, através de videoconferência. Em 2009, além dos cursos já mencionados, o Instituto UFC Virtual criou um curso presencial de Bacharelado em Sistemas e Mídias Digitais. Esse curso está voltado para a formação de profissionais da área de mídias digitais e compreendendo três habilitações: Comunicação em Mídias Digitais, Jogos Digitais e Sistemas de Informação Multimídia. Em 2010, O Instituto UFC Virtual, após aprovação do Conselho Universitário da UFC (Consuni), passou a ser considerado como unidade acadêmica, no caso, a 16ª da Universidade Federal do Ceará. A partir de então, foi criada, pela equipe gestora, a estrutura organizacional do Instituto Virtual, apresentada na Figura 2. 
Figura 2 - Estrutura organizacional UFC Virtual

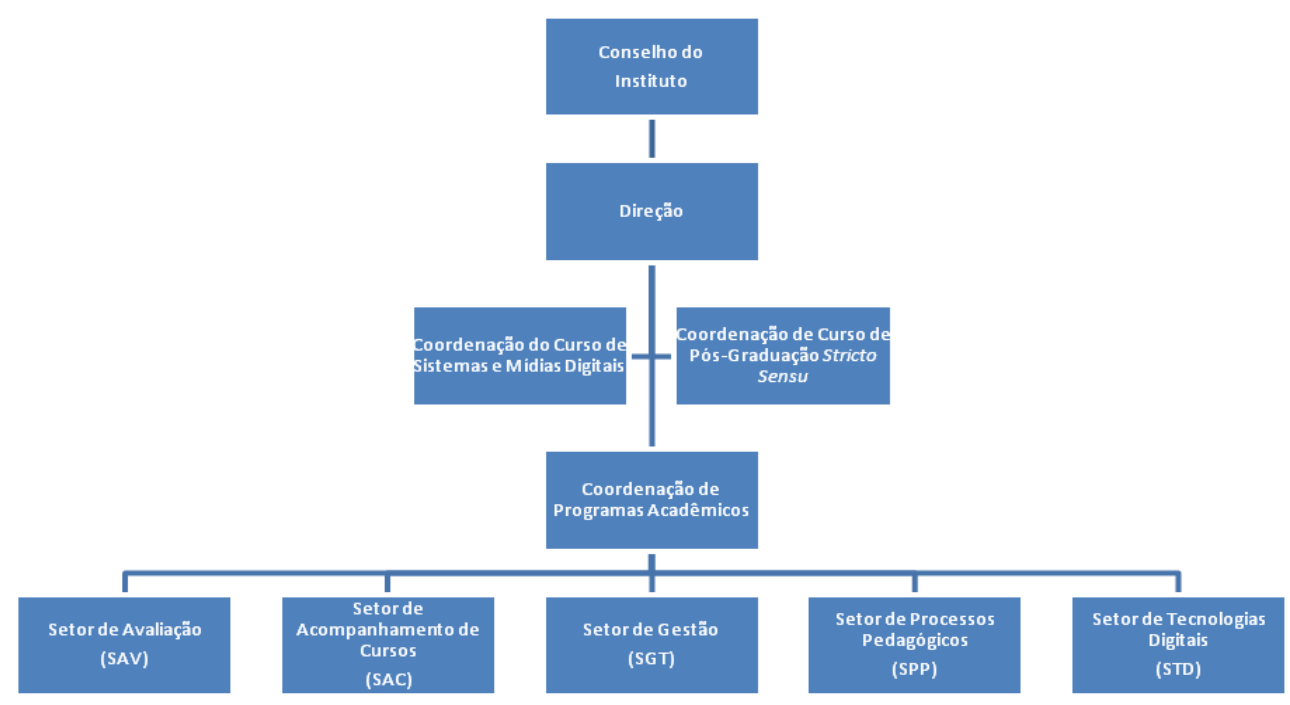

Fonte: Site oficial da UFC Virtual.

O Instituto UFC Virtual é constituído por uma Direção Geral, pelas Coordenações de Cursos de graduação e pós-graduação Stricto Sensu, pela Coordenação de Programas Acadêmicos e pelas Coordenações dos Setores nas diversas competências de atuação da Unidade. Pedagogicamente, o Instituto UFC Virtual se organiza da seguinte maneira (Figura 3):

Figura 3: Organização acadêmica do EaD na UFC Virtual

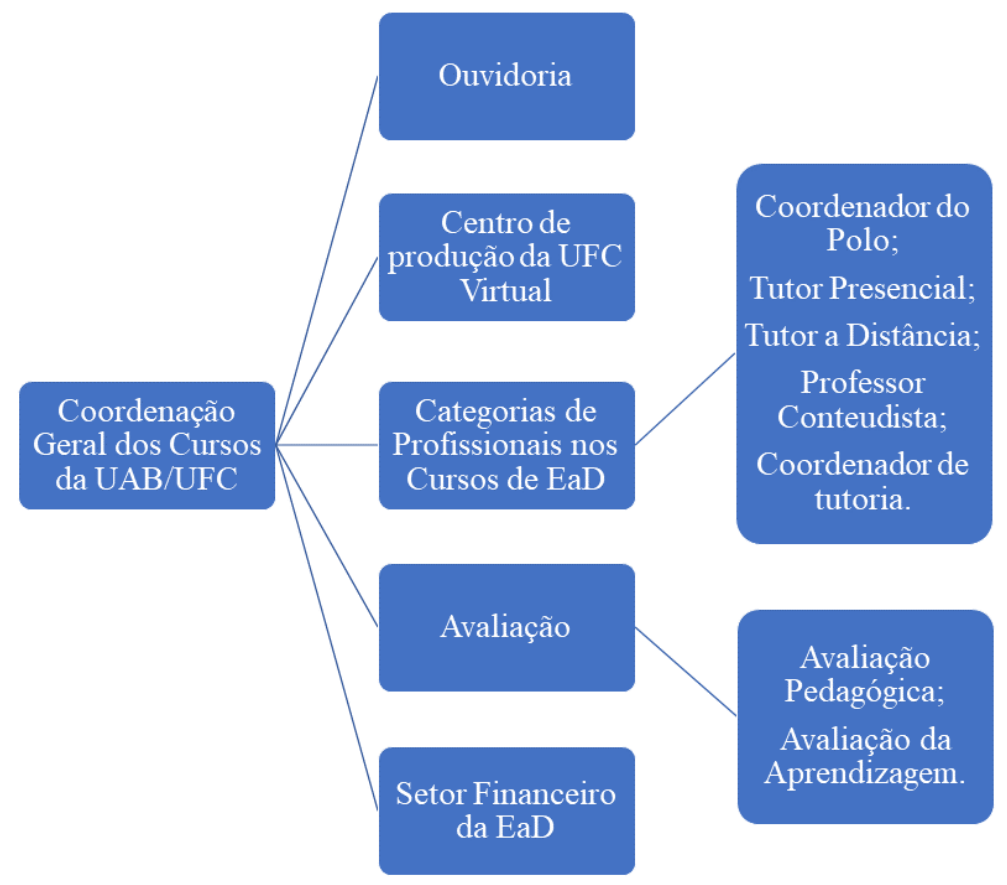

Fonte: Elaborado pelo autor com base em Quirino (2017) 
A coordenação tem um professor da Universidade Federal do Ceará, que atua nas atividades de coordenação geral do Sistema UAB na UFC; a ouvidoria é responsável pelo recebimento, encaminhamento e acompanhamento de críticas, denúncias, elogios e sugestões aos diversos setores do Instituto; O Centro de Produção é composto por uma equipe multidisciplinar de pedagogos, analistas de sistemas, programadores, designers e técnicos em áudio e vídeo.

Além disso, cada curso conta com um Coordenador de Curso, responsável pela elaboração do projeto pedagógico; um Coordenador de Polo, responsável pela gestão operacional do polo de apoio presencial; um Tutor Presencial, responsável pelo atendimento aos estudantes no polo, acompanhando e orientando os estudantes em todas as atividades que envolvem o processo de ensino-aprendizagem; Tutores a Distância, responsáveis pelo atendimento pedagógico aos estudantes por meio de encontros presenciais e de ferramentas de comunicação, disponíveis no Ambiente Virtual de Aprendizagem (correio eletrônico, fóruns, chat, webconferência etc.); Professores Conteudistas, responsáveis pelo planejamento da disciplina, elaboração do material didático e acompanhamento da execução da disciplina; e uma Coordenação de Tutoria, que intermedeia ações didático-pedagógicas junto às partes envolvidas nas diversas disciplinas do Curso (Professores Conteudista, Tutores e Discentes).

As avaliações são conduzidas sob dois aspectos:

- Avaliação Pedagógica do Curso: efetuada ao término de cada disciplina, considerando os seguintes aspectos: Recursos Humanos - desempenho do Professor Tutor; Atividades pedagógicas presenciais e a distância; Sistema de Avaliação da Disciplina; Infraestrutura: material didático e infraestrutura física.

- Avaliação da aprendizagem: é a avaliação final da disciplina, efetuada em conformidade com o planejamento pedagógico da mesma, divulgado no início do curso. Representa 60\% da composição da nota final (QUIRINO, 2017).

O Instituto conta ainda com um Setor Financeiro, responsável pela elaboração dos relatórios para dimensionamento de receitas/despesas dos projetos em EaD. De 2010 em diante, as políticas em educação a distância na Universidade 
Federal do Ceará têm se mantido estáveis, sem mudanças significativas. O Gráfico 1 mostra a evolução do número de matrículas durante o período de 2009 a 2018.

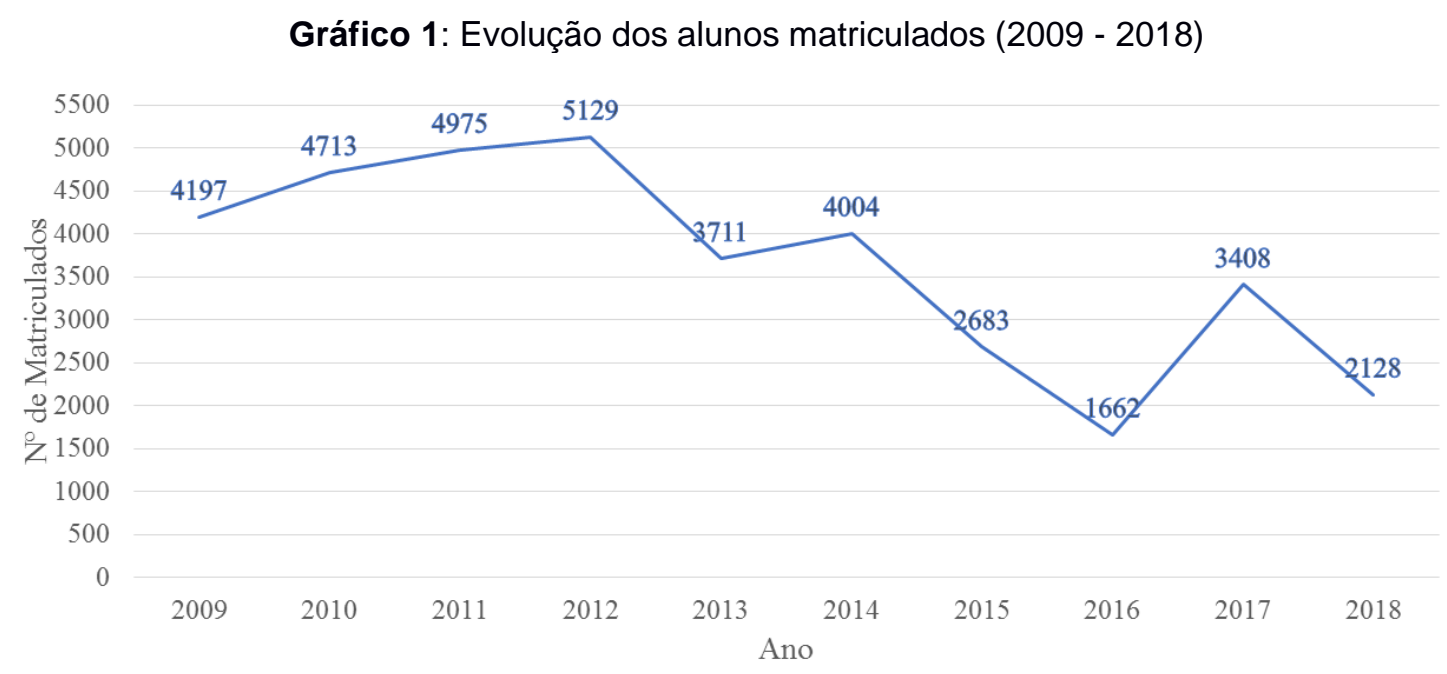

Fonte: Elaborado pelo autor com base no Anuário Estatístico da UFC 2019 base 2018.

Como mostra o Gráfico 1, entre os anos de 2009 e 2012, um crescimento vertiginoso no número de matrículas pôde ser observado. Saindo de 4197 matrículas em 2009 para 5129, em 2012. O que representa um aumento de mais de $22 \%$ em 4 anos. Esse crescimento, porém, foi seguido de grandes oscilações no número de matrículas entre os anos de 2013 e 2018, tendo como o número mais baixo da série histórica, 1662 matriculas em 2016, uma queda de mais de 60\% em relação ao ano anterior. Em 2017 voltou a subir (105,1\%), saindo dos 1662 de 2016 para 3408, em 2017. Em 2018 esse número caiu para 2128 matrículas.

Em 2019, a UFC já ofertava 9 cursos distribuídos em 28 polos (Aracati, Aracoiaba, Barbalha, Beberibe, Brejo Santo, Camocim, Campos Sales, Cariri, Caucaia, Fortaleza - IMPARH, Ipueiras, Itapipoca, Jaguaribe, Limoeiro do Norte, Maranguape, Meruoca, Missão Velha, Orós, Piquet Carneiro, Quiterianópolis, Quixadá, Quixeramobim - FATEC, Quixeramobim - UAB, Russas, São Gonçalo do Amarante, Sobral, Tauá e Ubajara), sendo eles: Bacharelado em Administração Gestão Pública, Bacharelado em Administração, Licenciatura em Física, Licenciatura em Letras Espanhol, Licenciatura em Letras Inglês, Licenciatura em Letras Português, Licenciatura em Matemática, Licenciatura em Pedagogia e Licenciatura em Química (UNIVERSIDADE FEDERAL DO CEARÁ, [201-], documento em linha). 
Para que as atividades em EaD fossem possíveis, foram desenvolvidos os Ambientes Virtuais de Aprendizagem (AVA). Os AVA são softwares educacionais facilitadores para a educação a distância via Internet, destinados a dar suporte às atividades de educação a distância (MARCUZZO, 2013). Para Santos (2003), um ambiente virtual é um espaço fecundo de significação em que seres humanos e objetos técnicos interagem, potencializando a aprendizagem.

A UFC, por sua vez, adota o Solar (Ambiente On-line de Aprendizagem), que recentemente foi desenvolvido também em versão para dispositivos móveis, o Solar Mobilis. O Solar é um ambiente virtual de aprendizagem desenvolvido pelo Instituto UFC Virtual, da Universidade Federal do Ceará. Ele é orientado ao professor e ao aluno, possibilitando a publicação de cursos e a interação com os mesmos (LABORATÓRIO DE MÍDIAS EDUCACIONAIS, [201-], documento em linha). Para Pessoa e Santos (2017 p. 4757) "o Solar é primordial para comunicação e avaliação dos alunos, além de proporcionar integração entre os atores da EaD nos Cursos de Graduação ofertados pela UFC". O Solar, atualmente (2020) está na sua versão 2.0 (Figura 4).

Figura 4 - Ambiente Virtual de Aprendizagem Solar

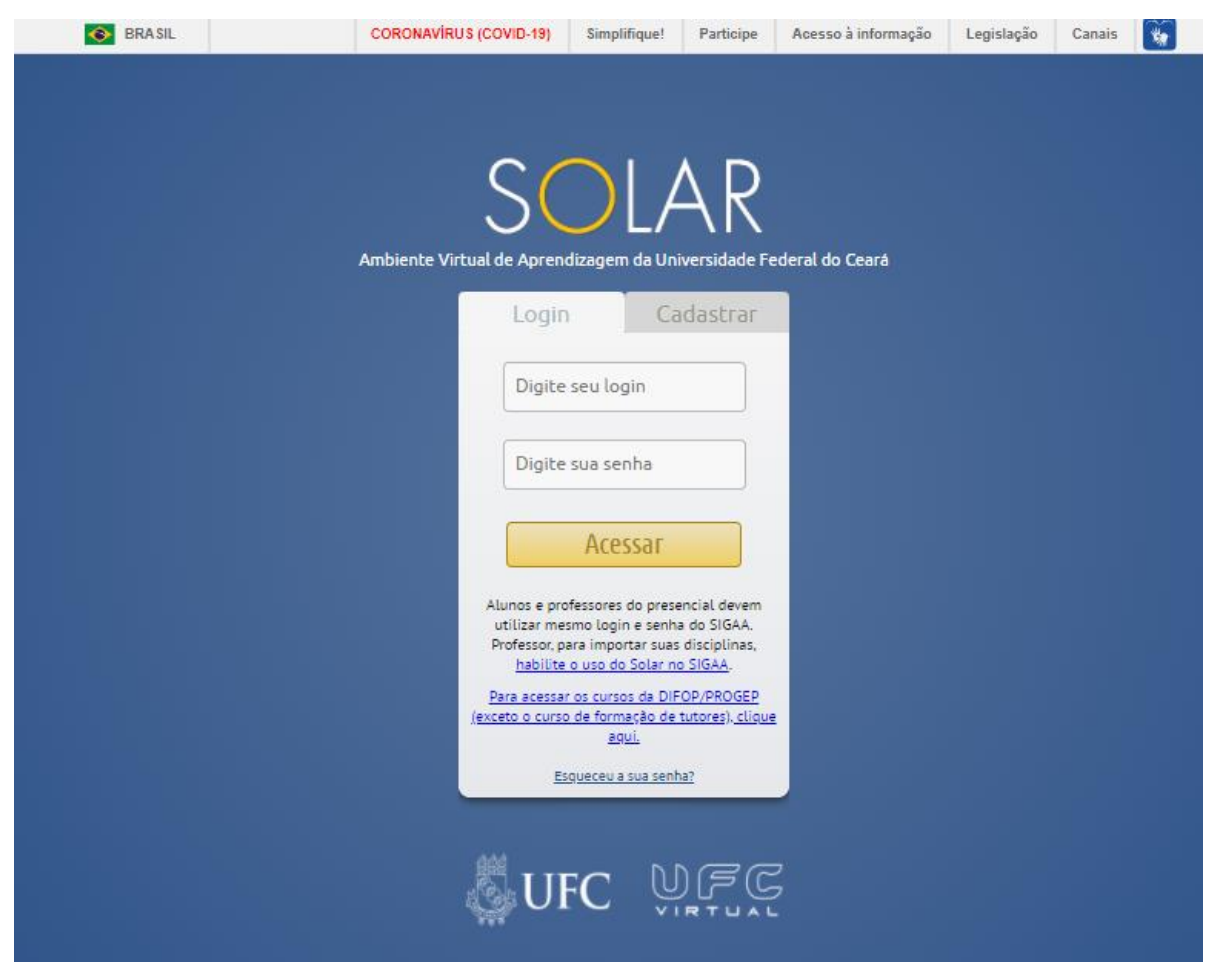

Fonte:www.solar.virtual.ufc.br 
A Figura 4 apresenta a página de login do Solar 2.0. Para ingressar, o aluno digita seu login e senha e desse modo tem acesso às disciplinas, aos fóruns, chats, materiais de apoio disponibilizados pelos professores, entre outros recursos oferecidos pela plataforma.

\section{Considerações finais}

Por sua brevidade, este trabalho não apresenta todas as experiências que contribuíram para o desenvolvimento da EaD no Brasil e na UFC, porém, busca destacar os pontos mais relevantes da longa e diversificada história da educação a distância no país e as tecnologias usadas em diferentes períodos de sua evolução.

Em seus primeiros anos, ainda na sua $11^{\circ}$ geração, o ensino era realizado através da mídia impressa e o envio de materiais por correspondência. Nesse período atuou principalmente no campo do ensino profissionalizante.

Com a popularização do rádio, no início do século $X X$, a $2^{2}$ geração começou a surgir. Essa geração foi caracterizada pelo uso não apenas do rádio, mas também de outras mídias, como: as fitas cassete, a televisão e o telefone. Teve como principais representantes, a Rádio Sociedade Educativa do Rio de Janeiro (1923) e o Instituto Rádio Monitor (1939) no início do século e o surgimento das TVs Educativas, que deram origem aos telecursos, a partir de 1965.

A $3^{\text {a }}$ geração começou a surgir no final dos anos de 1990, com o desenvolvimento das tecnologias de informação e comunicação. Essa geração se caracteriza pelo uso de tecnologias interativas, como: a Internet e a videoconferência. É marcada também pelo surgimento dos ambientes virtuais de aprendizagem. A partir de então, diversas instituições de ensino passaram a desenvolver programas de educação a distância baseados na Internet.

Nesse contexto, a Universidade Federal do Ceará tem desempenhado um papel fundamental na expansão e democratização do ensino superior no estado do Ceará, capacitando profissionais de diferentes áreas do conhecimento e atendendo a milhares de alunos que, por morarem em lugares distante da capital e/ou por serem de classes menos privilegiadas, jamais teriam a oportunidade de realizar um curso de graduação. Pode-se dizer que desde 2003, através do Instituto UFC Virtual, essa 
instituição tem atuado exitosamente, tanto na capital como no interior do estado, firmando-se como uma referência de educação a distância.

Pode-se concluir que a educação a distância no Brasil, apesar de ainda está atrasada em relação a outros países e de ter enfrentado vários percalços em sua trajetória, tem cumprido um papel fundamental na educação nacional, possibilitando a formação de vários profissionais técnicos, a capacitação de profissionais já graduados e o aumento substancial no número de matriculas no ensino superior. Vale salientar ainda que a EaD tem sido extremamente importante para a expansão e democratização do ensino no país, permitindo que o conhecimento alcance lugares que, sem a sua existência, jamais seria possível.

Além disso, conclui-se que a Universidade Federal do Ceará incorporou, de forma exitosa, a EaD em suas atividades acadêmicas e que, em 18 anos, desde a criação do Instituto UFC Virtual, tem contribuído fortemente para o aumento de números de matriculas na instituição e cumprido seu papel de levar a oportunidade de formação para as diversas regiões do estado do Ceará.

Este artigo buscou, através de uma pesquisa bibliográfica, apresentara evolução histórica da EaD no Brasil e a inserção da UFC nesse contexto. Desta forma, ele pode ser empregado na formação básica de professores para esta modalidade educacional e contribuir para estudantes ou curiosos interessados em conhecer a história da EaD no Brasil.

\section{Referências Bibliográficas}

ALVES, João Roberto Moreira. A história da EAD no Brasil. In: LITTO, Fredric M.; FORMIGA, Marcos. (Org.). Educação a distância: o estado da arte. São Paulo: Abed, 2009. Cap. 2. p. 9 - 13.

ALVES, Lucineia. Educação a distância: conceitos e história no Brasil. Revista Brasileira de Aprendizagem Aberta e a Distância, v. 10, p. 83-92, 2011.

ANDRIOLA, Wagner Bandeira. Avaliação da qualidade de curso online empregando o QEOn: estudo de caso. Revista Sustinere, Rio de Janeiro, v. 7, n. 2, p. 224-250, 2019.

ANDRIOLA, Wagner Bandeira; GOMES, Carlos Adriano. Programa um computador por aluno (PROUCA): uma análise bibliométrica. Educar em Revista, Curitiba, n. 63, p. 267-288, 2017. 
ANDRIOLA, Wagner Bandeira; LOUREIRO, Robson. Sistematização da avaliação da aprendizagem em comunidades organizadas no ciberespaço. Revista Iberoamericana de Educación, v. 37, n. 1, p. 1-6, 2005.

ANDRIOLA, Wagner Bandeira; OLIVEIRA, Karla Roberta Brandão. Auto-avaliação institucional na Universidade Federal do Ceará (UFC): meio século de história.

Avaliação: Revista da Avaliação da Educação Superior, Campinas, v. 20, p. 489512, 2015.

ARAUJO, Adriana Castro; ANDRIOLA, Wagner Bandeira; COELHO, Afrânio de Araújo. Programa Institucional de Bolsa de Iniciação à Docência (PIBID): desempenho de bolsistas versus não bolsistas. Educação em Revista, Belo Horizonte, v.34, e172839, 2018.

CARNEIRO, Antônio Lúcio da Cunha. A Evasão no Ensino Semipresencial: Estudo de Caso em um Polo de Apoio da UAB/UFC. 2010. Dissertação (Mestrado em Políticas Públicas e Gestão da Educação Superior) - Superintendência de Recursos Humanos, Universidade Federal do Ceará, Fortaleza, 2010.

KIPNIS, Bernardo. Educação superior a distância no Brasil: tendências e perspectivas. In: LITTO, Fredric M.; FORMIGA, Marcos. (Org.). Educação a distância: o estado da arte. São Paulo: Abed, 2009. Cap. 29. p. 209 - 2014.

LAVOR, João Ferreira; ANDRIOLA, Wagner Bandeira; LIMA, Alberto Sampaio. Avaliando o Impacto da Qualidade da Gestão Acadêmica no Desempenho dos Cursos de Graduação. Um Estudo em Universidade Pública Brasileira. Revista Iberoamericana de Evaluación Educativa, Santiago de Chile, v. 8, n. 2, p. 233254, 2015.

LIMA, Alberto Sampaio; ANDRIOLA, Wagner Andriola. Avaliação de prática pedagógicas inovadoras em cursos de graduação em Sistemas de Informação. Revista Iberoamericana sobre Calidad, Eficacia y Cambio en la Educación, Madrid, v. 11, n. 1, p. 104-121, 2013.

LIMA, Daniela da Costa Britto Pereira. Desenvolvimento, aprimoramento e consolidação de uma educação nacional de qualidade: educação a distância na educação superior. Brasília: Ministério da Educação, 2014. Disponível em: http://portal.mec.gov.br/index.php?option=com_docman\&view=download\&alias=1651 1- produto-02-estudo-processo\&ltemid=30192. Acesso em: 02 jun. 2020.

MAIA, Carmen.; MATTAR, João. ABC da EaD: a educação a distância hoje. São Paulo: Pearson, 2007.

MARCUZZO, Marlei Maria Veduim. A Satisfação dos Alunos de Educação a Distância da Universidade Federal de Santa Maria. 2013. Dissertação (Mestrado em Engenharia da Produção) - Centro de Tecnologia, Universidade Federal de Santa Maria, Santa Maria, 2013. 
PELLI, Débora; VIEIRA, Flávio César Freitas. História da educação na modalidade a distância. In: CONGRESSO INTERNACIONAL DE EDUCAÇÃO E TECNOLOGIAS, 2018, São Paulo. Anais [...] CIET: EnPED [S.I], 2018.

PESSOA, Samille dos Santos.; SANTOS, Osmundo Francisco Fernandes dos. A Análise do Ambiente Virtual de Aprendizagem Solar no Curso à Distância de Administração em Gestão Pública da Universidade Federal do Ceará no Polo de Camocim. Revista Encontros Universitário da UFC, v. 2, n. 1, 2017.

QUIRINO, Raimunda Heveline Ribeiro. Gestão da Aprendizagem no Ensino a Distância em Instituição de Ensino Superior Sob a Ótica dos Fatores Críticos de Sucesso. 2017. Dissertação (Mestrado em Políticas Públicas e Gestão da Educação Superior) - Superintendência de Recursos Humanos, Universidade Federal do Ceará, Fortaleza.

REIS, Roselene Maria de Vasconcelos. Cartografia da informática educativa em Fortaleza: mapeando cenários, identificando saberes dos atores formadores e interpretando a trama da história. 2005. Dissertação (Mestrado em Educação) Centro de Educação, Universidade Estadual do Ceará, Fortaleza, 2005.

RUBIO, Claudete Paganucci. Uma modalidade de ensino na educação: educação a distância. 2011. Tese (Doutorado em Serviço Social) - Faculdade de Ciências Humanas e Sociais, Universidade Estadual Paulista, Franca, 2011.

SANTIAGO, Larisse Barreira de Macêdo. História e memória da informática educativa no Ceará. 2017. Tese (Doutorado em Educação Brasileira) - Faculdade de Educação, Universidade Federal do Ceará, Fortaleza, 2017.

SANTOS, Edméa Oliveira dos. Ambientes de Aprendizagem: problematizando práticas curriculares. In: NOVA, Cristiane; ALVES, Lynn. (orgs). Educação e Tecnologia: Trilhando caminhos. Salvador: Editora da UNEB, 2003.

SILVA, Francisco César Martins da; LIMA, Alberto Sampaio; ANDRIOLA, Wagner Bandeira. REICE. Avaliação do Suporte de TDIC na Formação do Pedagogo. Um Estudo em Universidade Brasileira. Revista Iberoamericana sobre Calidad, Eficacia y Cambio en Educación, Madrid, v. 14, n. 3, p. 77-93, 2016.

UNIVERSIDADE FEDERAL DO CEARÁ. Anuário Estatístico da UFC 2009: Base 2008. Fortaleza: UFC, 2009. 419 p. Disponível

em:http://www.ufc.br/images/_files/a_universidade/anuario_estatistico/anuario_estati stico_ufc_2009_base_2008.pdf. Acesso em: 14 fev. 2021.

UNIVERSIDADE FEDERAL DO CEARÁ. Anuário Estatístico da UFC 2019: Base 2018. Fortaleza: UFC, 2019. 419 p. Disponível em: http://bit.ly/anuarioufc2019-2018. Acesso em: 21 abr. 2020. 
UNIVERSIDADE FEDERAL DO CEARÁ. Instituto UFC Virtual. Histórico. Fortaleza, [201-]. Disponível em: http://portal.virtual.ufc.br/index.php/sobre/. Acesso em: 27 jul. 2020.

UNIVERSIDADE FEDERAL DO CEARÁ. Laboratório de Mídias Educacionais. Solar Mobilis. Fortaleza, [201-]. Disponível em: http://palpatine.virtual.ufc.br/ webIme/wp-Ime/index.php/solar-mobilis/. Acesso em: 07 fev. 2021.

VALENTE, José Armando. Educação a distância no ensino superior: soluções e flexibilizações. Interface - Comunicação, Saúde, Educação, São Paulo, v. 7, n. 12, p.139-142, fev. 2003. Disponível em:

http://www.scielo.br/scielo.php?script=sci_arttext\&pid=\$1414-32832003000100010. Acesso em: 02 jun. 2019.

\section{Francisco Wagner de Souza \\ Fortaleza, Ceará, Brasil}

Mestrando em Políticas Públicas e Gestão da Educação Superior (Poleduc) na Universidade Federal do Ceará. Especialista em Ensino de Língua Espanhola pela Universidade Cândido Mendes (2017). Possui graduação em Letras - Espanhol pela Universidade Federal do Ceará (2014). Atualmente é professor de Língua Espanhola da Universidade Federal do Ceará e atua na Casa de Cultura Hispânica.

E-mail: prof.wagnersouza@ufc.br

Lattes: http://lattes.cnpq.br/7154500710515133

\section{João Welliandre Carneiro Alexandre}

Fortaleza, Ceará, Brasil

Graduado em Estatística pela Universidade Federal do Ceará (1985), mestrado em Estatística pela Universidade Estadual de Campinas (1989) e doutorado em Engenharia (Engenharia de Produção) pela Universidade de São Paulo (1999). Atualmente é professor Titular da Universidade Federal do Ceará. Atua nas áreas de pesquisas associadas à gestão pela qualidade e controle estatístico da qualidade. Tem interesse em desenvolver pesquisa nas seguintes linhas: modelos de gestão pela qualidade, teoria da resposta ao item aplicada à gestão pela qualidade, gráficos de controle estatístico do processo e confiabilidade de produtos.

E-mail: jwca@ufc.br

Lattes: http://lattes.cnpq.br/5234277371908895 


\section{Revista Labor}

Programa de Pós-graduação em Educação, Universidade Federal do Ceará

Fortaleza-CE-Brasil

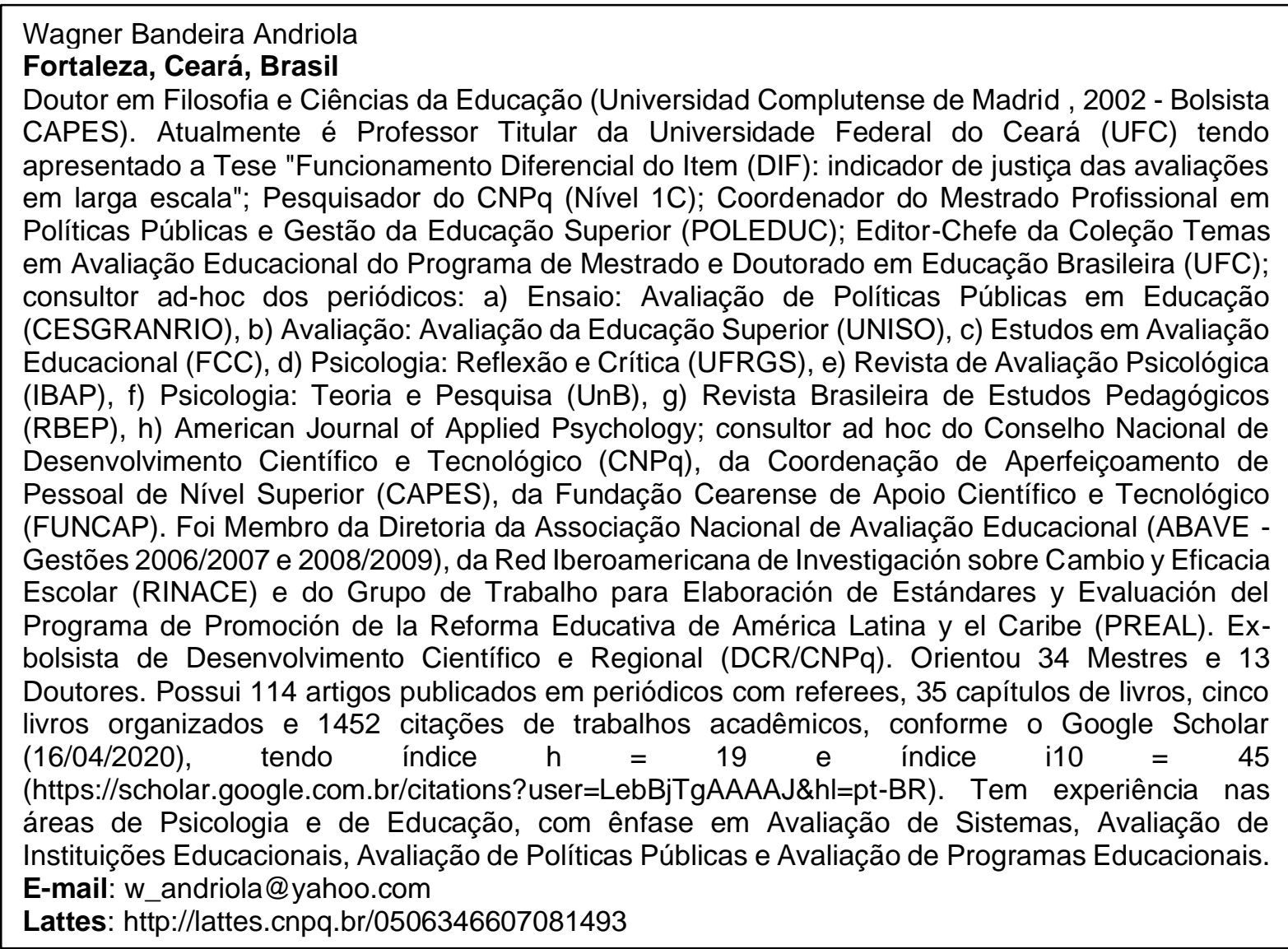

\section{Sueli Maria de Araújo Cavalcante \\ Fortaleza, Ceará, Brasil}

Doutora em Educação, eixo temático em Avaliação Institucional, com a tese "Avaliação da eficiência dos cursos de graduação da Universidade Federal do Ceará: utilização de indicadores de desempenho como elementos estratégicos de gestão", pela FACED/UFC (2011). Mestre em Engenharia de Sistemas e Computação pela Universidade Federal do Rio de Janeiro (1988). Graduada em Processamento de Dados pela Universidade Federal do Ceará (1978) e em Administração de Empresas pela Universidade Estadual do Ceará (1981). Atualmente é professora associada da Universidade Federal do Ceará. Tem experiência nas áreas de Administração e Informática, com ênfase em Administração de Sistemas de Informação. Membro do corpo docente do Mestrado Profissional em Políticas Públicas e Gestão da Educação Superior - Poleduc, da UFC. Professora do Curso de Administração à Distância, pela Universidade Federal do Ceará/ Universidade Aberta do Brasil.

E-mail: suelicavalcante@ufc.br

Lattes: http://lattes.cnpq.br/1962466876884560 


\section{Revista Labor}

Programa de Pós-graduação em Educação, Universidade Federal do Ceará

Fortaleza-CE-Brasil

Antônio Clécio Fontelles Thomáz

\section{Fortaleza, Ceará, Brasil}

Possui graduação em Matemática pela Universidade Federal do Ceará (1969), mestrado em Informática pela Pontifícia Universidade Católica do Rio de Janeiro (1973) e doutorado em Engenharia de Sistemas e Computação pela Universidade Federal do Rio de Janeiro (1986). PósDoutorado na Universidade Joseph Fourrier - Gfenoble França em 1995. Atualmente é Prof. Titular Aposentado da Universidade Federal do Ceará e Prof. adjunto da Universidade Estadual do Ceará. Tem experiência na área de Matemática, com ênfase em Matemática Discreta e Combinatória, atuando principalmente nos seguintes temas: otimização combinatória, programação linear, otimização industrial, otimização linear e programação matemática. Coordenador do Laboraqtório de Otimização e Gestão Industrial LOGIN da Universidade Estadual do Ceará onde desenvolve projetos na área de de otimização industrial até 05/07/2012. Aposentou-se pela UFC em 17/11/2000 Aposentou-se da UECE em 05/07/2012.

E-mail: clecio@larces.uece.br

Lattes: http://lattes.cnpq.br/1974142878046742

Recebimento: 22/02/2021

Aprovação: 24/05/2021

\section{Q.Code}

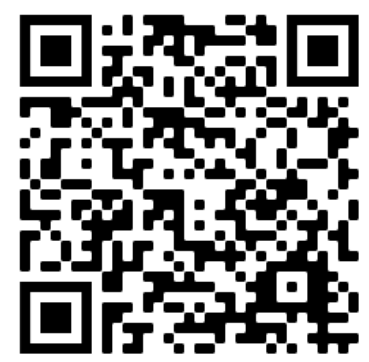

\section{Editores-Responsáveis}

Dr. Enéas de Araújo Arrais Neto, Universidade Federal do Ceará, UFC, Ceará, Brasil

Dr. Sebastien Pesce, Universidade de Orléans, França 